\title{
Narrative risks in science writing for the lay public
}

\section{Olav Muurlink and Peter McAllister}

\begin{abstract}
The narrative method of presenting popular science method promises to extend the audience of science, but carries risks related to two broad aspects of story: the power of narrative to impose a compelling and easily interpretable structure on discrete events and the unpredictability and mystique associated with story.
\end{abstract}

Keywords History of public communication of science; Science writing

Context

Science writing for the lay public frequently appears to degenerate into so-called 'Just So' stories: narrative explanations of evolutionary phenomena that do not conform to rigorous principles of scientific explanation. The term derived from Kipling's 1912 famous short stories of how creatures like elephants, camels and rhinos got their trunks, humps and skins. ${ }^{1}$ But how uncommon is the use of the fundamentals of narrative storytelling in popular science writing - and not just evolutionary phenomena? Bruner [1986] describes narrative and scientific explanation as "two modes of thought, each providing distinctive ways of ordering experience, of constructing reality. The two [though complementary] are irreducible to one another" (p. 11). They differ radically in structure, Bruner insists: scientific explanation follows that of the logical proposition "if $x$, then, logically, $y$ ", while narrative adopts the recitational formula "the king died, and then the queen died." The crucial difference here, of course, is notion of causality: in the first case, Bruner says, causality is seen as a question of universal truth conditions while in the second it is a matter of connections between two particular events (a queen does not invariably die shortly after a king). Norris et al. [2005] echo these generalities, describing narrative as unsuited to the circumspection and caution required in scientific explanation, and preoccupied with particularities as opposed to the search for general principles that are the ultimate goal of scientific enquiry.

They also, however, offer a quite specific critical analysis of the defining characteristics of narrative, contrasting them in each case with those of scientific explanation. Briefly, these are: narrative's character as a sequence of discrete, unique, unrepeatable and hence unpredictable events (at odds with the deductive-nomological drive of scientific explanation, where the aim is to reduce events to universal, general, inevitable and or repeatable actions); its incorporation of actors who

\footnotetext{
1"Once upon a most early time was a Neolithic man" begins Kipling's (1912) story about how the first letter was written.
} 
display agency, or the ability to alter behaviour and influence events (so different, again, to the realm of science, where the goal is to reduce the influence of agency, in those limited areas in which it exists); narrative's use of a narrator, who however disguised is still a potent intermediary with great power to pluck events out of the fabula (the background of things which reflects the chronological order in which they happened, rather than were recounted by the narrator) for rearrangement into the sujet, or plot, in which they are given meaning and the story told.

These terms derive from Russian Formalism, but as Walsh points out there are older and younger versions of these two: be Aristotle's muthos versus praxis, for example, or the $20^{\text {th }}$ century's discourse versus story [Walsh, 2001]. Regardless of which terms are used, the distinction they refer to alludes to a view of the author as more god than experimental scientist, for whom discriminative selection of elements from the fabula is positively frowned upon).

\section{Objective}

It is these fundamental differences that prompt Norris et al.'s pessimistic assertion that "the role of narrative in scientific explanation is limited" [Norris et al., 2005]. What they perhaps meant is that its role should be limited, when in fact - at least in popular science writing - it is very arguably not.

In tackling the question of why it should be limited, we will draw on two distinct disciplines, evolutionary biology and developmental psychology, both prone to narrative accounts, not just in popular science, and use as particular case studies two very different texts, Freud's 1901 landmark text, Psychopathology of Everyday Life, and a much more obscure and recent text, Peter McAllister's Pygmonia [McAllister, 2010]. These two texts are chosen for very different reasons. The first, because of its impact as both in the popular and scientific domains, and the second because of access to the author himself, which allows us insight into the difficulties of avoiding the narrative approach in writing about science. The inclusion of these two texts from two very different disciplines share a curious connection with the power of narrative that illuminate a problem not just in science writing, but, we argue, scientific thinking.

Evolutionary biology is almost in its essence a strongly narrative science, containing significant elements of contingency, timeframe and history [Norris et al., 2005; Journet, 1999; Morson, 1996], and the same point can be said for developmental psychology although the story plays out on a smaller timescale. That both fall into a narrative trap may be less to do with the natural fit between science and the 'packaging' that story offers and more to do with the appeal of story to the cognitive makeup of humans in general rather than scientists in particular. Some of the most enduring lifespan theories of how we come to be what we are as adults, in particular psychodynamic theories, have what Kenneth and Mary Gergen call a "storied nature" [Gergen and Gergen, 1986]. We will argue the storied nature of such scientific explanations, however, is rooted in two very different origins, what we term the 'law' and 'lore' origins of story. We will use Freud, who styled himself a scientist who attempted to bring determinism to psychology, to illustrate the general tension between 'lore' and 'law', and then turn to McAllister's text as a specific illustration of how these tensions play out in a modern piece of popular science writing. We will refer Norris et al.'s [Norris et al., 2005] four defining characteristics of narrative, and conclude by offering one way 
in which popular science writing can compel in the manner of true narrative, and still serve to advance science.

Law

In 1995 radical anthropologist Chris Knight proposed a startling new evolutionary explanation of human menstruation: it was a mechanism to signal reassuring sexual unavailability to men. "A firm sex strike," he wrote, "would have enabled females in effect to guarantee that during hunting-related absences there would be no sex... with rival, stay-at-home males," [Knight, 1995].

Knight's theory exhibits both the characteristics that critics level at 'Just So' stories. Firstly, it suffers from what Karl Popper [2002] called the 'ad hoc fallacy': it was "introduced... to explain a particular difficulty, but... cannot be tested independently". It remains, according to John Alcock, "one of the most successful derogatory labels ever invented" [Alcock, 2001]. Just So stories do not violate their own internal logic, yet make no real attempt to subject itself to external tests that might falsify it [Bamford, 1999; Schlinger, 1996]. An analysis of uterine shedding by other mammals, for example, would have shown that menstruation is probably just an artefact of the excessive thickness of Homo sapiens womb linings [Strassmann, 1996]. In Gould and Lewontin's terms (two of the most trenchant critics of evolutionary 'Just So' stories) this is the error of 'adaptionism' - the tendency to divide organisms' morphologies and behaviours into discrete traits and generate stories to explain them, accepting mere consistency with the principles of natural selection as verification. Both Popper's, and Gould and Lewontin's, criticisms imply, hence, that what makes these 'Just So' accounts so popular is their simple, unitary logic. In effect their violation of scientific principles is the cause of their appeal.

Knight's theory also exhibits the second criticism leveled at 'Just So' stories — that they are stories, and we will craft a definition of 'story' shortly, leaning on Norris et al.'s identified four defining characteristics of narrative [Norris et al., 2005]. Meanwhile, Knight's 'how the woman got her menstruation' account has face parity with Kipling's 'how the leopard got its spots'. This criticism (that an account is fabricated) is perhaps the most interesting and possibly the one that best explanation of the appeal of 'Just So' stories about scientific conundrums.

Such stories might, in other words, be easy to understand simply because the information in them is logically uncomplicated, as Popper, Gould and Lewontin imply. Alternatively, this ease of understanding might also be because the reader or listener has heightened skills in receiving and understanding information that is put into narrative form. There are several lines of evidence that suggest this might be the case. Bower and Clark [1969], in a classic study, found that individuals were able to remember twice as many random words when they were embedded in a narrative structure, suggesting that the narrative has great power as an organizing schema, or cognitive framework. "When adequately inclusive context is available," says Ausubel says of schemata, "new ideas can be assimilated... much more efficaciously, thereby facilitating both comprehension and retention of new material" [Ausubel, 1980], and herein lies the payoff of story. Readers have been shown to more rapidly comprehend written information in quicker, and remember it longer, when it is presented in narrative form [Forbes, 1999; Zabrucky and Moore, 
1999]. Boyd suggests states that human narrativising is both involuntary and capable of generating disproportionately large outputs from limited input - both hallmarks of adapted, instinctual behaviour [Boyd, 2009]. That aspect of the story that sees events that are not just linked in a random series, but linked in a sequence that implies cause and effect, is also likely to partially explain the power of the story. Heider and Simmel's famous experiment, in which viewers invented stories to explain random, inanimate dots, also suggests an inherent human propensity to narrativise [Heider and Simmel, 1944]. It also relates to our tendency to ascribe causality to temporally or otherwise proximal items. Cognitive psychologists have concluded that we have something approaching an "inability to consider events as being independent of each other" [Ladouceur, Paquet and Dube, 1996].

The appeal of story is a theme that emerged in literary criticism if anything earlier than in the cognition literature. Influential English literary critic I.A. Richards for example declared that "few minds could prosper if they had to work out an original... response to meet every situation that arose. They would be exhausted..." [quoted in Freund, 2013]. In turning to the story-like, we are finding a "narrative home for an anomalous happening. We are using language," says Donald Spence, a psychoanalytic theorist specifically referring to theory, which is in some senses the midpoint between story and schema, "to clothe [an] event in respectability and take away some of its strangeness and mystery...". ${ }^{2}$ We are hunting "a kind of linguistic and narrative closure" (137). We argue that this is one of the two contradictory aspects of story, the ability to impose structure, or law to chaos.

Freud saw himself in the tradition of Darwin the evolutionary scientist. In his groundbreaking Psychopathology of Everyday Life, Freud refers to his predecessor as the "great Darwin" [Freud, 1901], and there is a curious moment in this volume where he connects their two great bodies of work. He quotes Darwin as follows:

I had, during many years, followed a golden rule, namely, that whenever a published fact, a new observation or thought came across me, which was opposed to my general results, to make a memorandum of it without fail and at once; for I found by experience that such facts and thoughts were far more apt to escape from the memory than favourable ones [Darwin, quoted in Freud, 1901].

The observation becomes almost amusing, insofar that Freud lauds Darwin's honesty at the same time as casually working the statement into his own scheme of things ("the part played by unpleasure as a motive for forgetting") (199). He does not seem to recognise the threat to his own theoretical ecosystem from the pattern-dependent, pattern-alert nature of human cognition which we referred to earlier. So this is the first of the two characteristics of story that appeal equally to the psychology of scientists relating their findings, and their audience, the characteristic of story that imposes structure on a more or less loose and complex nature. We call this the law characteristic of story.

Physical phenomena, let alone psychological ones, are ambiguous, but Freud, himself with a far more acute than average grasp of the tendencies of human

\footnotetext{
"Scientific theories are constructed from a scaffold of narrative plots" [Gergen and Gergen, 1986, pp. 22-44].
} 
psychology, seems almost oblivious to this possibility in crafting his 'stories'. In one interpretation of a dream about a missing 'piece', he notes, referring to girls' penis-less state, that a boy "has a whole piece more than a girl" (89), when, if it had suited the context, he could have noted that a woman has, higher up on the body, two "pieces" more than a man. Freud was very human in this sense, needing to impose order upon the universe. At one point in the Psychopathology of Everyday Life, Freud makes a quite extraordinarily sweeping claim for psychoanalytic self-sufficiency in his comments on superstition. If phenomena other than the merely mentally-caused ones he admits to "were to be established" - for example he gives spiritualist events-"we should merely set about modifying our "laws" in the way demanded by the new discovery without being shaken in our belief in the coherence of things in the world" (324).

Elsewhere, Freud "invariably found" that forgetting could be traced to "unknown and unavowed motives" (206) and that "[nothing] is ever mislaid except as a result of unconscious intention" (194), with the same deep intentions at work "[e]very time we make a slip in talking or writing" (281), and even when taking a stab at a random number, Freud says, "we" are always in the company of our unconscious (our emphases). In one case he even says, challenging every reader, "[t]his instance cannot be explained in any other way" (167) (our emphases). It hardly needs repeating that Freud was no lay-person, but a highly trained and intelligent neurologist, who nevertheless found the need to pull facts into frameworks - not just in the aid of science, but in the aid of his own psychology. That Freud additionally considers story a persuasive medium is indicated by his ubiquitous use of the "psychoanalytic fictional genre par excellence" [De Lauretis, 1984], the case study, to "prove" his point, and indeed a glance at the number of italicised entries in the index of Everyday Life will indicate that Freud leans heavily on literary works (not the least Sophocles) for illustration, and, perhaps, advice. Story is a source of ideas. "[H]ow hard it is for a psychoanalyst to discover anything new that has not been known before by some creative writer." (262).

\section{Lore}

There is another aspect of the story quite distinct from its benefit in terms of rule and structure. Regardless of which therapy is delivered including 'nonsense' therapies created simply as controls for comparative studies, patients tend to recover equally well. Therapy, Spence [1984] and Totman [1979] amongst others argue, involves the creation of a narrative sufficiently compelling for the patient to enter into, where the match between the story and the 'listener' is more important than the truth of the tale. In a meta-analysis of psychotherapy 'component studies', that is, studies that pit a specific treatment against a treatment package without a component known or assumed to have therapeutic benefit, Ahn and Wampold [2001] found the "critical components" of key therapries did not have power significantly different from zero. They suggest the reasons is not that therapies are useless, but that there are useful elements common to all therapies. They suggest that part of this common element is a good match between therapist and patient, and patient belief "in the rationale for treatment and in the treatment itself" (p. 251). We suggest that therapies offer a compelling narrative, a story, that is believable without being too plain an explanation of a problem. We regard law then as being that aspect of the story that oversimplifies the facts, and lore as that aspect of the story that ensures that it retains mystery. 
Foucault has nicely described this tension, identifying psychoanalysis as something "at once ritual and scientific" [Foucault, 1990; qtd. in Rieff, 1987]. Freud treated the human mind less as a morass of evidence that could be tidied up by a number of simple biological laws, and more as a banquet of mysteries. For example, he tells of an interpretation of a man who had "accidentally" written to his wife suggesting she come over to Europe on the Lusitania, a ship which had by then sunk. "This slip of the pen needs no explanation," says Freud. "Its interpretation is perfectly plain." Read between the lines that it is unsatisfyingly plain, for he adds: "But $a$ happy chance enables a further point to be added" (our emphasis) [Freud, 1901], and goes on to thicken the plot. Elsewhere we have Freud saying of infantile amnesia, that "we fail to look upon it as a strange riddle" (86). For someone described by a biographer as a believer in the "universal validity of the law of determinism" [Strachey, 1962], there is an almost detective aspiration in his work. There are the echoes of Samuel Johnson the great biographer in Freud's words, where he declared that writers "lay on the watch for novelty" [quoted in Daiches, 1956]. Numerous authors have commented on the close fit between scientific inquiry and narrative forms involving quests - detective stories being a particularly apt genre [Milne, 1998; Silverstone, 1984; Silverstone, 1985; Curtis, 1994]. Yet science writing that involved the describing of the scientific method again and again would make for comparatively anodyne reading, at least within a popular science context.

It is possible that part of the appeal of Freud was in fact that he was so unlike his hero Darwin. Darwin's early critics claimed that the relatively simple principles of natural selection could not explain the evolution of complex structures and functions [Kingsolver and Koehl, 1994], but Freud was rarely criticised for excessive reductionism. In fact, in the volume of collected critiques of Freud's work, Against Freud, editor Todd Dufresne notes that even practioners are "routinely baffled by a field that defies understanding, even among those who make it their life's work" [Dufresne, 2007]. At one point Freud describes the paranoid. He says: "Everything he observes in other people is full of significance, everything can be interpreted." With an (unconscious?) eye upon himself he further remarks that "he sees more clearly than someone of normal intellectual capacity." (324). The literature on "depressive realism" [e.g. Pham, 2007] is based on the contention that depressed individuals make realistic inferences more regularly than 'normals'. There is a degree to which clear, unadulterated truths about oneself ("I am average") or about life ("it is $100 \%$ certain that I will be dead within a century") are challenging to human psychology. Humans seek a simple 'truth' (when the truth is more complicated) and a complex lie (when the truth is less interesting or too disturbing to face), and these delusions beset even those trained to avoid them. "Erroneous intuitions resemble visual illusions in that they remain compellingly attractive even when the person is fully aware of their nature," argue cognitive psychologists Daniel Kahneman and Amos Tversky writing on the fallacies that dog even experts [Kahneman and Tversky, 1977].

The four characteristics of narrative
Norris et al. [2005] have isolated four defining features of narrative. The first characteristic that distinguishes narrative from scientific exposition is the structural issue of its building blocks, as we noted in the earlier example of the king and the queen's death. To put it more formally, Norris et al. argue, narrative is composed of a sequence of discrete, unique, unrepeatable and hence unpredictable events, all of which took place in the past and are connected by a chain of meaning. This 
description echoes Bruner's [Bruner, 1986] characterisation of narrative as concerned with the local and particular, rather than the pursuite of universal truth common to scientific inquiry, but the distinction can be made much finer than that. The discrete and unique events defined by Norris, Guilbert et al. correspond to the unique 'tokens' described by Aristotelian philosophy, something akin to the anecdote, an identifiable narrative cluster that is an "essentially dramatic and immediate form, presenting the reader with an instance in which an aspect of the subject's character is vividly displayed" [Rayner, 1987; Marshak, 1972].

On the other hand, scientific inquiry under the deductive-nomological model is more concerned with the Aristotelian category of generalised 'types' [Modrak, 1979]. Because the structural units of narrative are unique and unrepeatable event-tokens, they are unpredictable, which seems to be an essential element of the 'narrative appetite' that adds to the form's appeal. Combined with the fact that narrative always describes past events (even with time travel fiction describing future events, the narrator is still relating events that took place in his or her personal past) this ensures that narrative cannot involve any element of prediction, but is instead characterised by a focus on retrodiction. Yet this, as Norris, Guilbert et al. state, conflicts with the central mission of the deductive-nomological model of scientific enquiry, in which the aim is to draw out general, universal principles on which scientific prediction can be based. Equally, in writing journal articles, authors are encouraged to think of limits to the generalisability of results, whereas in writing fiction, the universal message behind the anecdote is implied. Thus, the focus on the local, the discrete, the unique and the unpredictable that characterises narrative would seem to render it unsuitable for scientific inquiry under the deductive-nomological model. Many critics however rightly point out that there are numerous forms of scientific inquiry and explanation that are not deductive-nomological in nature [Morson, 1996; Cleland, 2002].

The second essential characteristic of narrative, as identified by a number of authors is that its characters all exhibit agency: they cause events, rather than just experience them [Bal, 1985; Cohen and Shires, 1988; Polkinghorne, 1988; Mattingly, 1991]. This, again, seems to be another respect in which humans are adapted to interact with narrative. Boyd [2009] outlines several experimental results that indicate humans are geared to think in terms of agency (we detect movement, for example, far quicker in animals than in cars). The ability to display agency implies a facility to choose among varying responses - which is, of course, the engine of the unpredictability noted earlier as central to narrative appetite, and the enduring appeal of biography, even the current trend toward 'biographies' of inanimate objects like soap and salt, underlines the case [Muurlink and McAllister, 2015].

Agential actors, however, are anathema to deductive-nomological science, where the aspiration is to strip agency from all entities involved - starting with the scientist (who is usually, in any case, the character with most agency in any given scientific experiment or investigation) [Montgomery, 1995]. Freud's role in creating and describing psychodynamic theory is the picture of agency, but as a scientist, he is by no means unique. Muurlink [1998] writing about psychological research in general asks:

Is it possible that as researchers, [it is not so much that] we want valid results, but simply... we want results, and that we have tightly controlled independent 
and dependent variables not simply to ensure that these variables are indeed responsible for our results, but because we want to be responsible for our results [Muurlink, 1998].

Many objects of scientific inquiry, of course, do not have any agency to begin with: hydrochloric acid does not decide whether or not to combine with sodium hydroxide and produce salt and water, for example. Some authors, by contrast, adopt the view that agency is not a necessary component of narrative, the existence of a sequence of causally connected events being of greater importance [Abbott, 2002; Ireland, 2001]. They cite, in this respect, stories such as Primo Levi's 'Carbon' from his book The Periodic table, in which readers trace the 'life course' of a particular carbon atom, an entity to which a sequence of events occurs, but which does not display agency. We argue, however, that while Levi has achieved one element of narrative - by focusing on an individual atom he has shifted frame from the general to the particular, allowing a sequence of causally related events the lack of agency prevents his text from rising to the level of truly engaging narrative. This is because, as several authors point out, agency (the ability to choose between courses of action that have consequences for the chooser) is essential for that sense of purpose and emotional engagement without which storytelling is rendered less lifelike and more artificial [Mattingly, 1991; McEwan and Egan, 1995].

The third fundamental characteristic of narrative, identified by Norris et al., is the presence of 'someone telling', that is, a narrator.

For authors such as Scholes and Kellogg [1966] this characteristic is, in fact, the one most diagnostic - any text in which there is a narrator telling is, by definition, a narrative. On some levels this seems both a blindingly obvious and arid observation: surely every text, even an expositional one, has 'someone telling', no matter how "backgrounded or remote or 'invisible' "[Toolan, 1988]? In fact, though, the narrator plays a specific and exceedingly powerful role in narrative forms, beyond the mere telling, as the intermediary between the fabula and the sujet. Nor is this only a matter of selectively arranging the event-tokens in such a way as to increase the text's narrative appetite, though that certainly is one of the narrator's functions [Genette, 1980]. More crucial is the narrator's role as interpreter, for it is by her selection of event-tokens from the fabula and their arrangement in the sujet that the meaning that is so crucial to distinguishing narrative from mere text is created.

The narrator, states Lodge [1986], determines both the point and the purpose of narrative: the narrator, like Freud picking and choosing elements of a dream to foreground, is in the powerful position of editor in this regard. At first glance this does not seem to necessarily be at great variance to the mechanics of scientific explanation. Scientific exposition, after all, similarly features 'someone telling'. Nor does the scientific ideal of objectivity - in which the scientist ideally removes all traces of herself from the text, leaving behind a hopefully neutral, dispassionate account - cause any real difficulties; recall Toolan's observation that narrators in narrative accounts may also be quite unobtrusive. The real problem is that the mission of scientific inquiry does not allow the 'teller' in these accounts to perform the same discriminative, interpreting role in picking events out of the fabula (in this case the raw scientific data) for assembling into the sujet (in this case the communication of her results). The scientist, duty bound to report every event-token in the fabula in full, without discrimination, is ideally barred from 
performing the crucial function of selection to create narrative appetite, but also, more importantly, to create meaning and purpose. ${ }^{3}$ In reality, in the real history of the publishing of science it is the winners - cases where hypotheses (or anticipation) are supported, and where statistical significant results are privileged over the rest of the dull, null hypotheses-strewn fabula, is a lot more complicated than that [see for example Scargle, 2000, on the 'file drawer' problem]. Peer reviewers of science papers are in quite a different position to literary critics, in that they have the right to demand greater access to data or to demand a re-write.

The fourth and final defining characteristic of narrative is its transformational dynamic. This is partly a structural issue; numerous authors have commented on the template that all stories seems to follow: beginning, middle and end [Gudmundsdottir, 1995; Roth, 1989]. This, again, seems spectacularly uninformative, except that these three divisions each mark a different stage in the transformational dynamic. Bal [1985] labels the three stages: the possibility, the event, and the result. van Peer and Chatman [2001], similarly, describe the stages as: imbalance, attempts at redress in the face of complications and obstacles, and eventual success or failure. So far this too causes no conflict with the deductive-nomological model of scientific explanation; Sheehan and Rode [1999] note that scientific articles commonly follow exactly the same structure of: problem, methodology for addressing that problem, and finally resolution. Landau [1984], similarly argues that scientific theories are often narratives, with the classic psychological paper for example detailing experiments laid out in a row with one emerging from another, like a naturally developing storyline. A closer look reveals, however, that this correspondence is at least in theory illusory. True, any given text of scientific explanation does start with a problem (ignorance and lack of clarity), that gives rise to a mystery, often expressed as the research question or hypothesis. This mystery is then addressed by a protagonist (the researcher) and which is transformed into a new state (that of knowledge) with both detectives (and their authors) and scientists engaged in the search for the same thing: 'proof'.

Yet in science this transformation does not occur within the domain of the object under study, where the general principles that the deductive-nomological model seeks to distil from repeated, non-unique event-types remain operative, but in the thoroughly human, particular and unique worlds of the researcher, writer and reader. In true narrative, by contrast, the worlds of the unique and individual actors within the text are transformed from one state to another, and it is this element that seems essential for engaging storytelling. Miller [1995] perhaps comes closest to this in his statement that true narrative involves a final "revelation". In order to be fully drawn in, it seems, the reader needs to be presented with an account that shows the transformation of the world of an agent or actor with whom the reader can empathise. In all four of the defining features of story, then, scientific explanation has been shown to have some basic incompatibilities with the narrative form. Perhaps, however, knowledge of these problems might allow an author to more fruitfully reconcile the two?

\footnotetext{
${ }^{3}$ True, this is sometimes more honoured in the breach, as Medawar [1964] points out. Even the aspiration, however, places strong constraints on the science narrator's freedom.
} 
The 'Just So' story revisited.

It is useful to briefly take an example of modern popular writing in evolutionary science, Peter McAllister's Pygmonia [McAllister, 2010]. Pygmonia was published by a university press and from the perspective of this study was promisingly described by a reviewer as balancing a "kaleidoscope of information" in aid of "scientific explication with longer stretches of narrative prose" [McGregor, 2012].

The book begins with a mystery, 'The Pygmy Question' (whether the world's disparate pygmy populations came from a single geographical source) which clearly satisfies the primary requirement of something needing scientific explanation: it is a 'why' question, or one about causation [van Fraassen, 1980]. The book reveals that the nice, enclosed narrative of a single world of 'little people' was eroded by subsequent discoveries - pygmy peoples turned out to be more closely related to their own taller neighbours than they were to each other [Graydon et al., 1958; Boyd, 1963; Omoto, 1985], however McAllister reveals how the original scientific Just So story of the 'one world' of the pygmies endured long after it was damaged, echoing's Kuhn's [Kuhn, 2012] work on the stubbornness of paradigms [Grounds and Ross, 2010; Ballard, 2006; Tindale and Birdsell, 1941].

The author of Pygmonia also does what is common in popular science writing: converts event-types of deductive-nomological explanation into event-tokens of narrative. These increase the narrative power of the work, but at the expense of pure science. To take just one hypothesis - that of shorter growth periods making for an early start to reproduction in high mortality, rainforest environments - the particular events in this instance are the myriad deaths of larger-sized women who died again and again, throughout the course of Pygmy peoples' evolution, leaving only the smaller women behind. What makes these deaths event-types? Surely, as things that happened to individual humans, they are narrative event-tokens? The difference is one of focus. To paraphrase Stalin's famous quote one proto-Pygmy woman's death is a tragedy, and a narrative event-token; tens of thousands are a statistic, and an event-type. It is, in fact, the very act of deriving the general law allowing prediction (in this case, that humans in high mortality, rainforest environments will experience selective pressure towards a Pygmy body form) that strips the retrodiction and the narrative out of each woman's story and turns it from token to type. What drives our narrative appetite is hearing the story of one woman, or at most a few woman; we cannot sustain emotional engagement in the story of ten thousand women. So the author can make the story more interesting by adding an ingredient of anecdote to the story, but these additions do not in any way bridge the chasm between explanation and narrative, but merely circumvent it, i.e., the explanation is still given in expository text sections but these are diluted by the addition of external narrative. To extend the analogy, they are not spice, embedded within the ingredients, but sparkle, appliqued to the surface.

One example is where McAllister relates the rediscovery of African Pygmies by European explorers. This could have been incorporated as bland and neutral description, as per the conventions of the deductive-nomological model. The author instead chooses to focus on the story of one particular explorer, however, Henry Morton Stanley, infusing the text with a dramatic cargo of agency. ${ }^{4}$ Also,

\footnotetext{
4Stanley was almost a caricature of pure agency; the Bakongo peoples christened him Bula Matari
'Smasher of Rocks' due to his bloody-minded determination to push on with his exploratory mission,

${ }^{4}$ Stanley was almost a caricature of pure agency; the Bakongo peoples christened him Bula Matari
'Smasher of Rocks' due to his bloody-minded determination to push on with his exploratory mission, whatever the obstacles.
} 
since these human sources of agency are peripheral, very little violence is done to the work's mission of scientific explanation.

McAllister, interestingly, but by no means uniquely, tries other, more novel devices to enliven his text, naming the pygmy theory for the first time (Pygmonia) to better enable a theoretical framework itself to become engaging, and be a player in the narrative, but it is hard to believe that the theory itself is interestingly at peril, any more than Primo Levi can make us hang breathlessly on the carbon atom's moral quandary as to which chemical compound to incorporate itself into next, lament its disastrous choice, or celebrate its triumphs.

Interestingly, although the situation is largely the same for the objects of evolutionary scientific explanation, the quirk of our minds noted by Boyd [2009] - that we tend to over interpret the presence of agency in actions of any kind prevents us from recognising this, just as Freud oscillates between the two peaks of agency and determinism. We almost always conceive of evolution as an active process driven by the organism itself. We describe it using active verbs

- organisms evolve, they adapt — and evolutionary theorists describe a species' evolutionary trajectory as its 'strategy' even though species and organisms are, in reality, the passive clay of the evolutionary process.

The third conflict between narrative and deductive-nomological explanation is the differing role of the narrator - whereas in theory, scientific reports could conceivably be machine written, the narrator of the story has a more creative role, plucking event-tokens out of the fabula for translation into the sujet. This interpretative role of the narrator in narrative has two goals: creating narrative appetite, and imbuing the narrative with meaning and purpose.

At first glance the first of these - the translation of pieces of explanatory evidence into event-tokens that can create narrative appetite - also seems problematic.

Recall that, in order to create such appetite, event-tokens must send the narrative lurching off into unpredictable directions. If everything is 'just so', it ceases to have the pull of suspense.

The trouble is science does not always fit the needs of narrative. A theoretical advance or discovery may not have any affect for many decades — witness the forty-year of hiatus between when Wegener's theory of continental drift was first proposed and finally accepted. Sometimes it may not be accepted at all. One particular scientific discovery that McAllister turned into an event-token in the writing of Pygmonia illustrates how this problem may nonetheless be overcome. This is the discovery of the African Saldahna Skull, a Homo heidelbergensis fossil, by archaeologist Ronald Singer in 1953 [Singer, 1954]. In terms of scientific explanation, the significance of this is that it undermines the theory proposed by Julius Kollman at the turn of the century that Pygmy people represented a 'Missing Link' between chimps and humans (since Homo heidelbergensis was known to be on the line of human ancestry, the fact that a tall heidelbergensis fossil had been found in Africa, where both Pygmies and chimps live today, made the idea that short chimps had evolved into short Pygmy humans there an absurdity). Hence, McAllister turned this into a crucial event-token in Pygmonia: a plot point that severely imperilled the survival of the main protagonist of the book - the anthropological theory of Pygmonia itself. The problem, however, is that nobody saw it as such at 
the time. Hence, turning the discovery into an event-token that prompted a twist in the narrative is not historically correct. This does not do excessive violence to the text's explanatory mission, since the event-token is still true in the sense that it carries logical force, but it does show the compromise that acting as a narrative narrator forces upon any author when they are trying to create narrative appetite in a deductive-nomological text.

Much more problematic, however, is the second function of the narrative narrator: that of imbuing the text with meaning and purpose. It is precisely this function, for example, that is responsible for the ideological freighting of 'Just So' stories noted earlier. We noted earlier that there was a basic structural divergence between narrative and deductive-nomological explanation: whereas the former is characterised by transformation from one state to another, the latter concerns itself with description of steady states and the laws that can be derived from them. Yet even this is not the deepest conflict between the two. The real problem is the baggage of meaning and purpose that the dynamic transformation inherent to narrative implies. Boyd [2009], in outlining his theory of the evolutionary origins of storytelling, theorises that the function of narrative is to allow readers to exercise their social intelligence, quoting Dennett as saying we do this "to refine our resources by incessant tinkering and rehearsal" (292). This seems to account for the structural template of narrative mentioned earlier — imbalance, attempts at redress, and eventual success or failure.

The stories that engage us are those that posit an unfamiliar and stressful situation - complete with characters that are proxies of the self, or enemies and allies - that we can imagine ourselves in and experience the resolution of, thereby extending our emotional and social capabilities. To experience the transformation in stories is to undergo transformation ourselves, if only vicariously. Yet this is also the dimension of narrative that makes it most unsuited to deductive-nomological explanation. It is why explanation put into narrative form so easily ends up carrying moral, political and ideological meaning - we take the neutral data of explanation and attempt to morph it into the transformational battlefield our narrative-adapted brains expect to find, complete with heroes, villains and other characters too. The history of attempted explanation of Pygmy origins is littered with examples of this tendency. The Gesta Romanorum, a moralising tract written by an English Franciscan friar in 1342, stated that the small stature and feebleness of Pygmies reflected their lack of perseverance in the struggle against the deadly vices. We take a current state and retrospectively load it with theories about causation. Stories, in summary, are apt to tell us stories.

\section{Conclusions}

What then for popular science writing - is there no way out without falling into the trap of 'Just So' stories and the way they satisfy the two hidden allures of law and lore? Is the narrative form simply inimical to scientific explanation? Or can the inherent advantages the narrative form is granted by our apparent adaptation to it be harnessed to write effective evolutionary texts that are nonetheless true to the science?

Fundamental conflicts have been identified in every one of Norris et al.'s [Norris et al., 2005] four defining characteristics of narrative; these were sometimes insurmountable and sometimes not. Event-types, for example, are not amenable to 
being treated as event-tokens in science writing, and science writers instead invest the particular with general meaning. Agency, similarly, cannot readily be identified or simulated in the objects of scientific explanation and has to be sought in external sources. The role of narrator proved a little more adaptable, and perhaps even too adaptable. Freud's work is a classic example of a powerful storyteller selecting ingredients with great discrimination from the fabula to increase the narrative flavor of the sujet - in fact his is an extreme example of the narrative becoming the science. In creating a popular science 'story', the author needs to create what writer's term a 'spine' that connects the whole account, that drives it forward from an initial, attention-grabbing start to a final, strongly-enunciated end, maintaining a strong focus on the story's point the whole way and ensuring every single word highlights that point and contributes to the drive towards the destination, allowing few or no digressions. In Norris, Guilbert et al.'s more neutral language, this is a combination of the 'sequence of event-tokens' and the 'purpose' that is one of the narrator's two aims in assuming the responsibility of selective translation from the fabula to the sujet. Yet the need to identify and avoid the pitfalls of the 'Just So' story complicated this at every turn, because that narrative through-line is exactly what defines a 'Just So' story.

We showed how it was possible to anthropomorphise theory itself, as in the case of Mcallister's invention of 'Pygmonia', to aid the reader in caring about the death or otherwise of an idea. In principle, it should be possible to put one theory up against another, in a manner that supports Popper's notion of falsifiability, allowing the anthropomorphized text to stick more closely to scientific method, airing opposing views, and using evidence to elevate one over the other.

If the 'theory as protagonist' technique is, then, a reasonably safe tactic for the popular science writer, it also has the advantage of being applicable to any branch of science, not just evolutionary science or biology. An example can be seen in works on Wegener's theory of continental drift, mentioned above. Most texts written on Wegener's theory have fallen wholly to either side of the narrative/explanatory divide. Several biographies of Wegener, for instance, have given narrative accounts of the man himself, but only incidental explanation of his theory [Schwarzbach, 1986; Yount, 2009; Young, 2009]. Other, explanatory, texts have outlined Wegener's theory in expository text, but have included little narrative beyond sketchy biographies [Edwards, 2005]. At least one text on Wegener's theory, however, has taken a similar approach to that recommended here. The real protagonist of Oreskes' [Oreskes, 2003] account of Wegener's theory's journey to acceptance, Plate Tectonics: an Insider's History of the Modern Theory of the Earth, is the theory of continental drift itself. Another example is Sobel's [Sobel, 2010] Longitude, which ostensibly is the biography of an idea, but is really assembled around the skeletal biography of the progenitor of that idea.

While Sobel emphasized one protagonist, Oreskes', her technique of allowing multiple players in the development of plate tectonics theory allows her to create a vivid narrative full of gripping stories of opposition, acceptance and eventual victory - a compelling journalism/biography of one particular science that manages to still leave the reader with a thorough understanding of continental drift. The story has the discrete, unique unrepeatable elements of history, the issue of agency and a narrator telling the story does not disturb the scientific value of the drama, and context between the competing theories sees the 'winning' theory 


\section{References}

transformed, modified, tested, and proven hardy in battle. At least in this limited sense, the narrative form offers the author a matrix in which science can be presented in a structured sense that includes engagement and suspense without critically sacrificing science.

Abbott, H. P. (2002). The Cambridge Introduction to Narrative. Cambridge, England: Cambridge University Press.

Ahn, H. n. and Wampold, B. E. (2001). 'Where oh where are the specific ingredients? A meta-analysis of component studies in counseling and psychotherapy'. Journal of Counseling Psychology 48 (3), p. 251.

Alcock, J. (2001). The triumph of sociobiology. Oxford, U.K.: Oxford University Press.

Ausubel, D. P. (1980). 'The facilitation of meaningful verbal learning in the classroom'. In: Written Communication: Selected Readings. Ed. by J. Hartley. London, U.K.: Kegan Paul, pp. 16-25.

Bal, M. (1985). Narratology: Introduction to the Theory of Narrative. Toronto: University of Toronto Press.

Ballard, C. (2006). 'Strange Alliance: Pygmies in the Colonial Imaginary'. World Archaeology 38 (1), pp. 133-151.

Bamford, G. (1999). 'What is the Problem of Ad Hoc Hypotheses?' Science E Education 8 (4), pp. 375-386.

Bower, G. H. and Clark, M. C. (1969). 'Narrative stories as mediators for serial learning'. Psychonomic Science 14 (4), pp. 181-182.

Boyd, B. (2009). On the Origin of Stories. Cambridge, MA, U.S.A.: Belknap Press.

Boyd, W. C. (1963). 'Four Achievements of the Genetical Method in Physical Anthropology'. American Anthropologist, New Series 65 (2), pp. 243-252.

Bruner, J. (1986). Actual Minds, Possible Worlds. Cambridge, MA, U.S.A.: Harvard University Press.

Cleland, C. E. (2002). 'Methodological and Epistemic Differences Between Historical Science and Experimental Science'. Philosophy of Science 69, pp. 474-496.

Cohen, S. and Shires, L. M. (1988). Telling Stories: A Theoretical Analysis of Narrative Fiction. New York, U.S.A.: Routledge.

Curtis, R. (1994). 'Narrative Form and Normative Force: Baconian Story-Telling in Popular Science'. Social Studies of Science 24, pp. 419-61.

Daiches, D. (1956). Critical approaches to literature. Upper Saddle River, NJ: Prentice-Hall.

De Lauretis, T. (1984). 'Alice doesn't: Feminism, semiotics, cinema'. In: A Midland book Language, discource, society. Vol. 316. U.S.A.: Indiana University Press.

Dufresne, T. (2007). Against Freud: critics talk back. Stanford University Press.

Edwards, J. (2005). Plate Tectonics and Continental Drift. London: Evans Brothers Ltd.

Forbes, C. (1999). 'Getting the Story, Telling the Story: The Science of Narrative, the Narrative of Science'. In: Narrative and Professional Communication. Ed. by J. M. Perkins and N. Blyler. Stamford, CT, U.S.A.: Apex Publishing Corporation, pp. 79-92.

Foucault, M. (1990). The History of Sexuality, Volume 1: an Introduction. Hardmondsworth: Penguin.

Freud, S. (1901). 'The Psychopathology of Everyday Life'. In: The Standard Edition of the Complete Psychological Work of Sigmund Freud (1960). Ed. by A. Strachey. Trans. by A. Tyson. Vol. 6. London, U.K.: Hogarth Press. URL: http://www.pep-web.org/document.php?id=se.006.0000a. 
Freund, E. (2013). Return Of Reader. London, U.K.: Routledge.

Genette, G. (1980). Narrative Discourse. Oxford: Basil Blackwell.

Gergen, K. J. and Gergen, M. M. (1986). 'Narrative form and the construction of psychological science'. In: Narrative psychology: The storied nature of human conduct. Ed. by T. R. Sarbin. Westport, CT, U.S.A.: Praeger Publishers/Greenwood Publishing Group, pp. 22-44.

Graydon, J. J., Semple, N. M., Simmons, R. T. and Franken, S. (1958). ‘Blood Groups in Pygmies of the Wissellakes in Netherlands New Guinea'. American Journal of Physical Anthropology 14 (2), pp. 149-171.

Grounds, S. and Ross, A. (2010). 'Constant Resurrection: the Trihybrid Model and the Politicisation of Australian Archaeology'. Australian Archaeology 70, pp. 56-67.

Gudmundsdottir, S. (1995). 'The Narrative Nature of Pedagogical Content Knowledge'. In: Narrative in Teaching, Learning, and Research. Ed. by K. H. E. McEwan. New York, U.S.A.: Teachers University Press, pp. 24-38.

Heider, F. and Simmel, M. (1944). 'An Experimental Study of Apparent Behavior'. American Journal of Psychology 57 (2), pp. 243-259.

Ireland, K. (2001). The Sequential Dynamics of Narrative: Energies at the Margins of Fiction. London: Associated University Presses.

Journet, D. (1999). 'The Limits of Narrative in The Construction of Scientific Knowledge: George Gaylord Simpson's The Dechronization of Sam Magruder'. In: Narrative and Professional Communication. Ed. by J. M. Perkins and N. Blyler. Stamford, Connecticut, U.S.A.: Apex Publishing Corporation, pp. 93-102.

Kahneman, D. and Tversky, A. (1977). Intuitive prediction: Biases and corrective procedures. DTIC Document.

Kingsolver, J. G. and Koehl, M. (1994). 'Selective factors in the evolution of insect wings'. Annual review of entomology 39 (1), pp. 425-451.

Knight, C. (1995). Blood Relations: Menstruation and the Origins of Culture. Eastbourne, U.K.: Antony Rowe Ltd.

Kuhn, T. S. (2012). The structure of scientific revolutions. University of Chicago press.

Ladouceur, R., Paquet, C. and Dube, D. (1996). 'Erroneous perceptions in generating sequences of random events'. Journal of Applied Social Psychology 26, pp. 2157-2166.

Landau, M. (1984). 'Human evolution as narrative: have hero myths and folktales influenced our interpretations of the evolutionary past?' American Scientist 72 (3), pp. 262-268. URL: http://www. jstor. org/stable/27852647.

Lodge, D. (1986). 'Narration with Words'. In: Images and Understanding. Ed. by H. Barlow, C. Blakemore and M. Weston-Smith. Cambridge, England, U.K.: Cambridge University Press, pp. 141-153.

Marshak, A. (1972). The roots of civilisation. London, U.K.: Weidenfelf and Nicolson.

Mattingly, C. (1991). 'Narrative Reflections on Practical Actions: Two Learning Experiments in Reflective Storytelling'. In: The Reflective Turn: Case Studies in and on Educational Practice. Ed. by D. A. Schön. New York, U.S.A.: Teachers College Press.

McAllister, P. J. (2010). Pygmonia: In Search of the Secret Land of the Pygmies.

McEwan, H. and Egan, K. (1995). 'Introduction'. In: Narrative in Teaching, Learning, and Research. Ed. by K. H. E. McEwan. New York, U.S.A.: Teachers University Press, pp. vii-xv. 
McGregor, R. (2012). 'Pygmonia: In search of the secret land of the pygmies [Book Review]'. Aboriginal History 36, p. 217.

Medawar, P. (1964). 'Is the Scientific Paper a Fraud?'

Miller, J. H. (1995). 'Narrative'. In: Critical Terms for Literary Study. Ed. by F. Lentricchia and T. McLaughlin. Chicago, U.S.A.: University of Chicago Press, pp. 66-79.

Milne, C. (1998). 'Philosophically Correct Science Stories? Examining the Implications of Heroic Science Stories for School Science'. Journal of Research in Science Teaching 35 (2), pp. 175-187.

Modrak, D. K. W. (1979). 'Forms, Types, and Tokens in Aristotle's Metaphysics'. Journal of the History of Philosophy 17 (4), pp. 371-381.

Montgomery, S. L. (1995). The Scientific Voice. New York: Guildford Publications.

Morson, G. S. (1996). Narrative and Freedom: The Shadows of Time. New Haven: Yale University Press.

Muurlink, O. T. (1998). 'Olav Muurlink responds to Simon Kennedy'. Australian and New Zealand Journal of Family Therapy 19 (2), pp. 89-91.

Muurlink, O. T. and McAllister, P. J. (2015). 'The Biographizing Trend in Popular Science Writing'. The International Journal of the Book 13 (3), pp. 1-4.

Norris, S. P., Guilbert, S. M., Smith, M. L., Hakimelahi, S. and Phillips, L. M. (2005). 'A Theoretical Framework for Narrative Explanation in Science'. Science Education 89 (4), pp. 535-563.

Omoto, K. (1985). 'The Negritos: Genetic Origins and Microevolution'. In: Out of Asia: Peopling the Americas and the Pacific. Ed. by R. Kirk and E. Szathmary. Canberra, Australia: The Journal of Pacific History Inc., pp. 124-131.

Oreskes, N. (2003). Plate Tectonics: an Insider's History of the Modern Theory of the Earth. Boulder, Colorado: Westview Press.

Pham, M. T. (2007). 'Emotion and rationality: A critical review and interpretation of empirical evidence'. Review of general psychology 11 (2), p. 155.

Polkinghorne, D. E. (1988). Narrative Knowing and the Human Sciences. Albany, NY, U.S.A.: State University of New York Press.

Popper, K. (2002). The Logic of Scientific Discovery. London, U.K.: Routledge Classics.

Rayner, A. P. (1987). 'From Life-Writing to Biography: The Emergence of the Anecdote in the Seventeenth Century'. Masters Thesis. Montreal, Canada: Department of English, Concordia University. URL: http://spectrum. library. concordia.ca/3329/.

Rieff, P. (1987). The triumph of the therapeutic: Uses of faith after Freud. University of Chicago Press.

Roth, P. A. (1989). 'How Narratives Explain'. Social Research 56, pp. 449-478.

Scargle, J. D. (2000). 'Publication bias: the "file-drawer" problem in scientific inference'. Journal of Scientific Exploration 14 (1), pp. 91-106.

Schlinger, H. D. J. (1996). 'How the Human Got Its Spots: A Critical Analysis of the Just So Stories of Evolutionary Psychology'. Skeptic Magazine 4 (1), pp. 68-76.

Scholes, R. and Kellogg, R. (1966). The Nature of Narrative. Oxford University Press: New York, U.S.A.

Schwarzbach, M. (1986). Alfred Wegener: The Father of Continental Drift. Science Tech Pub.

Sheehan, R. J. and Rode, S. (1999). 'On Scientific Narrative'. Journal of Business and Technical Communication 13 (3), pp. 336-358.

Silverstone, R. (1984). 'Narrative Strategies in Television Science: A Case Study'. Media, Culture E Society 6, pp. 377-410. 
Silverstone, R. (1985). Framing Science: the Making of a BBC Documentary. London: BFI Publishing.

Singer, R. (1954). 'The Saldanha Skull from Hopefield, South Africa'. American Journal of Physical Anthropology 12 (3), pp. 345-362.

Sobel, D. (2010). Longitude: The true story of a lone genius who solved the greatest scientific problem of his time. Bloomsbury Publishing U.S.A.

Spence, D. P. (1984). Narrative truth and historical truth: Meaning and interpretation in psychoanalysis. WW Norton \& Company.

Strachey, J. (1962). 'Sigmund Freud: A sketch of his life and ideas'. In: Civilization, society and religion: Group psychology civilization and its discontents and other works, pp. 11-26.

Strassmann, B. I. (1996). 'The Evolution of Endometrial Cycles and Menstruation'. The Quarterly Review of Biology 71 (2), pp. 181-220.

Tindale, N. and Birdsell, J. B. (1941). Results of the Harvard-Adelaide Universities Anthropological Expedition, 1938-1939. Tasmanoid Tribes in North Queensland. Adelaide: S.A. Museum.

Toolan, M. J. (1988). Narrative: A Critical Linguistic Introduction. London: Routledge.

Totman, R. (1979). Social causes of illness. London, U.K.: Souvenir Press.

van Fraassen, B. C. (1980). The Scientific Image. Oxford: Clarendon.

van Peer, W. and Chatman, S. (2001). 'Introduction'. In: New Perspectives on Narrative Perspective. Albany, NY, U.S.A.: State University of New York Press, pp. 1-17.

Walsh, R. (2001). 'Fabula and fictionality in narrative theory'. Style 35 (4), p. 592.

Young, G. (2009). Afred Wegener: Pioneer of Plate Tectonics. Mankato: Compass Point Books.

Yount, L. (2009). Alfred Wegener: Creator of the Continental Drift Theory. New York: Chelsea House.

Zabrucky, K. M. and Moore, D. (1999). 'Influence of Text Genre on Adult's Monitoring of Understanding and Recall'. Educational Gerontology 25 (8), pp. 691-710.

Authors

Dr. Olav Muurlink is a psychologist and senior lecturer in organisational behaviour at Central Queensland University (Brisbane) and senior research fellow (adjunct) at Griffith Institute of Educational Research. E-mail: o.muurlink@gmail.com.

Dr. Peter McAllister is an author and anthropologist. His books include Pygmonia and Manthropology published by University of Queensland Press and St. Martin's Press respectively. E-mail: pmcallister@bigpond.com.

\section{How to cite}

Muurlink, M. and McAllister, P. (2015). 'Narrative risks in science writing for the lay public'. JCOM 14 (03), A01. 